J. Clin. Chem. Clin. Biochem.

Vol. 25, 1987, pp. $483-486$

(C) 1987 Walter de Gruyter \& Co. Berlin · New York

\title{
An Improved Spectrophotometric Procedure for the Determination of Urinary Metanephrines
}

\author{
By J.W. Stroes, J. Putters and H.J.M. van Rijn \\ Clinical and Haematological Laboratory, Dr. A. Mathijsen Hospital, Utrecht, The Netherlands
}

(Received January 5/April 30, 1987)

Summary: Spectrophotometric assays for urinary metanephrines are still widely used because of the simple equipment needed. These methods, however, have the major drawback of being very susceptible to interference. Using the original Pisano technique (Pisano, J. J. (1960) Clin. Chim. Acta 5, 406-414) we have often observed overestimation of the metanephrine concentration. By measuring absorbances at three different wavelengths we were able to considerably reduce this positive bias. With many patients this resulted in a significant downward adjustment of the values found for the total metanephrine excretion.

\section{Introduction}

Measurement of urinary metanephrines is probably one of the most reliable methods for the diagnosis of phaeochromocytoma (1-4). Although only about $0.04 \%$ (4) to $0.6 \%$ (1) of hypertensive patients suffer from this catecholamine-secreting tumour, exclusion of this possibility is extremely important, because unrecognised phaeochromocytoma often leads to fatal complications.

In the last decade many sophisticated techniques like high performance liquid chromatography, mass spectrometry and radio-immuno assays have been employed in assessing nanomolar concentrations of catecholamines and their derivatives $(5-10)$. However the expensive equipment needed is not within the reach of every laboratory. For this reason the simple colorimetric assay developed by Pisano (11) is still being used. In this assay metanephrines are converted to vanillin after hydrolysis and subsequent separation by ion-exchange chromatography. Vanillin is measured spectrophotometrically. Since the maximal absorbance at $347 \mathrm{~nm}$ lacks specificity, the concentration is usually calculated from the absorbance at $\mathbf{3 6 0}$ $\mathrm{nm}$, a wavelength less susceptible to interference. Although this reduces the number of erroneously high results, we still observed slight to significant overestimation of the daily secretion in many urines containing small amounts of metanephrines.

Determination of urinary metanephrines is used as a screening procedure: clearly excessive metanephrine excretion is seldom found. Unfortunately the borderline between "normal" and "elevated" is not always distinct. It has been reported that metanephrine excretion in some patients with proven phaeochromocytoma can be very close to the normal range $(2,6,12)$, especially in patients with intermittent hypertension. Overestimation of the excretion in "normal" urines would result in an extension of the grey zone in which diagnosis cannot be ascertained on biochemical grounds. For this reason, a slight overestimination of the metanephrine excretion can definitely be of clinical importance, even when the result is still within the normal range. By means of a method of calculation based on the absorbance at three different wavelengths we were able to reduce this positive bias considerably. Moreover, applying this method to the modified Pisano technique in our laboratory led to the "normal values" being adjusted downwards, thus reducing the number of results which might have introduced an element of doubt in the diagnosis. 


\section{Materials and Methods}

Urine samples were collected for 24 hours in bottles containing $30 \mathrm{ml} 4 \mathrm{~mol} / 1 \mathrm{HCl}$. Aliquots representing $1 / 200$ of the 24hour volume in duplicatc and $5 \mathrm{ml}$ of standards $(42.8 \mu \mathrm{mol} / \mathrm{l}$ metanephrine $\cdot \mathrm{HCl}$ ) in triplicate were hydrolysed, separated by ion-exchange chromatography on Amberlite CG-50 and treated with $\mathrm{NaIO}_{4}$ and $\mathrm{Na}_{2} \mathrm{~S}_{2} \mathrm{O}_{5}$ according to the orginal Pisano method (11), with the minor modifications suggested by Crout et al. (13).

All reagents were purchased from Merck (Darmstadt, FRG), except for $D, L$-metanephrine hydrochloride, $p$-hydroxybenzaldehyde and $D, L$-octopamine which were obtained from Sigma Chemical Co. (St. Louis. MO, USA) and Amberlite CG-50 which was obtained from Serva (Heidelberg, FRG).

Absorbance spectra were recorded using a Spectronic 2000 UV/ Vis spectrophotometer (Bausch \& Lomb Analytical Systems Div., Rochester NY, USA), scan speed $200 \mathrm{~nm} / \mathrm{min}$, slit width $2 \mathrm{~nm}$, lamp change (tungsten to deuterium) $380 \mathrm{~nm}$. Data (wavelength and corresponding absorbance) were transmitted through a RS-232 interface to a HP-85 microcomputer (Hewlett Packard Co, Corvallis OR, USA). The absorbance after subtraction of the blank (urine not treated with $\mathrm{NaIO}_{4}$ ) was used for calculations. Results were obtained after correction for recovery by use of the standards.

\section{Results and Discussion}

Normetanephrine and metanephrine are both converted to vanillin by treatment with $\mathrm{NaIO}_{4}$ in $4 \mathrm{~mol} / \mathrm{l}$ $\mathrm{NH}_{4} \mathrm{OH}$. This compound yields a broad absorption band with a maximum at approximately $347 \mathrm{~nm}$. Measurements are usually made at longer wavelengths, i. e. $360 \mathrm{~nm}$, to reduce the influence of interfering substances. Nevertheless, due to the shallow absorbance curve of vanillin it is not surprising that some compounds which are eluted with metanephrine are known to interfere with the metanephrine determination. Especially octopamine, which reacts in the same way with $\mathrm{NaIO}_{4}$ as metanephrine, yielding $p$ hydroxybenzaldehyde with a maximum at $333 \mathrm{~nm}$, is a known interferent. Where this compound is present in appreciable amounts, measurement at $360 \mathrm{~nm}$ easily leads to considerable overestimation of the metanephrine concentration (fig. 1). For this reason, Crout et al. (13) suggested that urines with an absorbance at $360 \mathrm{~nm}$ exceeding 0.063 (corresponding to $5 \mu \mathrm{mol}$ metanephrine per 24 hours) should also be measured at 347 and $333 \mathrm{~nm}$ in order to establish whether the high reading is due to vanillin or to an interfering substance with a maximum at a shorter wavelength, presumably $p$-hydroxybenzaldehyde. This procedure is useful in detecting erroneously high results, but it does not satisfy the requirement for reliable quantitative results where such interference is present. Other interfering compounds could be synephrine, which has been identified in bovine adrenal gland (15) and $p$-hydroxy-mandelic acid which can be demonstrated in human urine (15). However,

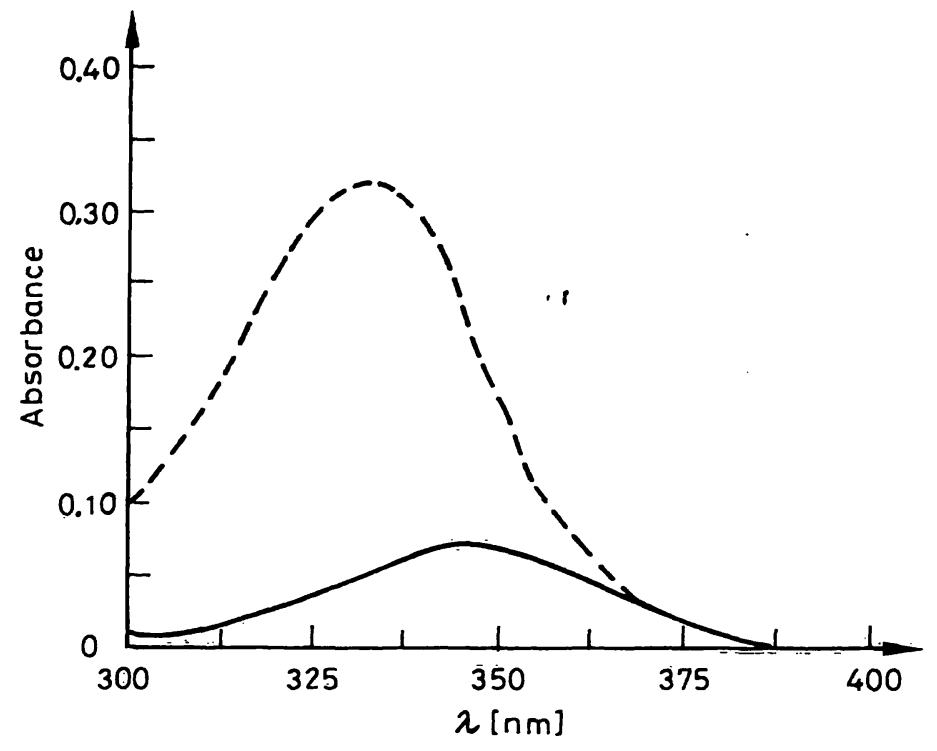

Fig. 1. Absorbance spectrum of $1.6 \mu \mathrm{mol} / 1$ vanillin $(-)$ and the absorbance spectrum of a mixture of $1.6 \mu \mathrm{mol} / 1$ vanillin and $10.7 \mu \mathrm{mol} / 1 \mathrm{p}$-hydroxybenzaldehyde $(--)$ in $4 \mathrm{~mol} / 1 \mathrm{NH}_{4} \mathrm{OH}$.

after oxidation with sodium metaperiodate these substances are also converted to $p$-hydroxybenzaldehyde, which allows the elimination of interference from three compounds by determination of one mutual oxidation product.

It appeared that virtually all spectra could be described satisfactorily as a mixture of vanillin, $p$-hy= droxybenzaldehyde and a constant background absorption. These three variables can be adequately calculated from the absorbances at three different wavelengths. Absorbances of the pure compounds were determined, which resulted in three equations:

$A_{400 \mathrm{~nm}}=0 \times[$ vani $]+0 \times[\mathrm{pOHbenz}]+\mathrm{c}$
$\mathrm{A}_{360}=0.0227 \times[$ vani $]+0.0037 \times[\mathrm{pOHbenz}]+\mathrm{c}$
$\mathrm{A}_{333}=0.0203 \times[$ vani $]+0.0268 \times[\mathrm{pOH}$ benz $]+\mathrm{c}$

where [vani] $=$ vanillin concentration in $\mu \mathrm{mol} / 1$

[pOHbenz $]=p$-hydroxybenzaldehyde concentration in $\mu \mathrm{mol} / \mathrm{l}$

$c=$ constant

Measurement at $400 \mathrm{~nm}$ proves to be important in eliminating the influence from background absorption. Since the absorbance of vanillin or $p$-hydroxybenzaldehyde is virtually zero at this wavelength, the " $c$ " in our equations equals the resulting absorbance at $400 \mathrm{~nm}$. The concentration of vanillin and $p$ hydroxybenzaldehyde can be calculated from the remaining two equations by simple elimination of unknown variables, followed by correction for recovery and for dilution caused by the addition of $\mathrm{NaIO}_{4}$ and $\mathrm{Na}_{2} \mathrm{~S}_{2} \mathrm{O}_{5}$. 
In our laboratory the measured $p$-hydroxybenzaldehyde concentrations were $5.0 \pm 6.0 \mu \mathrm{mol} / 24 \mathrm{~h}$ (mean $\pm \mathrm{SD} ; \mathrm{n}=39$ ). Unfortunately we were not able to determine the relative contributions of octopamine, synephrine and $p$-hydroxy-mandelic acid. The normal excretion of octopamine $(0.34 \pm 0.16 \mu \mathrm{mol} /$ $24 \mathrm{~h} ; 16$ ) and synephrine (less than $0.26 \mu \mathrm{mol} / 24 \mathrm{~h}$; 15) cannot explain these $p$-hydroxybenzaldehyde concentrations. On the other hand, $p$-hydroxy-mandelic acid with a normal daily excretion of $12.6 \pm 4.7$ $\mu \mathrm{mol} / 1$ for females and $17.2 \pm 8.6 \mu \mathrm{mol} / 1$ for males (15) could explain high $p$-hydroxybenzaldehyde concentrations.

This however seems unlikely for the following reason. Amberlite CG-50 is a cation exchanger, which binds the metanephrines, and octopamine and synephrine, via their nitrogen groups.

Chromatographic recovery of 3,4-dihydroxyphenylmandelic acid from plasma is $67 \pm 2.9 \%$ on a $\mathrm{Nu}$ cleasil C18 colomn coated with tri- $n$-butyl-phosphate (17), which retains carboxylic acids. Precautions were taken to avoid decomposition of the labile 3,4-dihydroxyphenyl-mandelic acid and elution was performed at $\mathrm{pH} 3$.

Because a metanephrine excretion close to $5 \mu \mathrm{mol}$ per 24 hours, i. e. the upper limit of normal metanephrine excretion, might leave doubts in reaching a diagnosis when phaeochromocytoma is strongly suspected on clinical grounds, we also adopted this calculation for urines showing absorbances at $360 \mathrm{~nm}$ below 0.053 . This often resulted in a considerable downward adjustment of the metanephrine excretion: many values close to or just above $5 \mu \mathrm{mol}$ per 24 hours were reduced to clearly normal results. Reference values as determined with our method were also reduced considerably compared with values derived solely from the absorbance at $360 \mathrm{~nm}$. In our laboratory, the mean 24-hour excretion for normotensive and hypertensive patients together was reduced from 2.8 $\pm 1.3 \mu \mathrm{mol}$ to $1.6 \pm 0.8 \mu \mathrm{mol}(n=39)$. The reference values found do not differ from results in the literature, obtained with more sophisticated techniques (tab. 1). In contrast, reference values found with the orginal Pisano technique or modifications thereof $(11-14)$ are consistently higher (tab. 1). It appeared that metanephrines in urine samples. of patients including patients with proven phaeochromocytoma as determined with gas chromatography according to the method of Muskiet (5) correlated well with the metanephrine values as determined with the present method. A correlation coefficient $r=0.998$ was found in 7 urine samples with values in the range between $1.1-102.6 \mu \mathrm{mol} / 1$.
Tab. 1. Mean urinary metanephrine excretion in non-phaeochromocytoma patients.

\begin{tabular}{lcl}
\hline $\begin{array}{l}\text { Methods used* } \\
\text { Reference }\end{array}$ & $\begin{array}{l}\text { Metanephrine } \\
(\bar{x} \pm s) \\
\mu \mathrm{mol} / 24 \mathrm{~h}\end{array}$ \\
\hline GC/MS & $(5)$ & $1.0 \pm 0.4^{* *}$ \\
RIA & $(6)$ & $0.5 \pm 0.2$ \\
MS & $(7)$ & 2.0 \\
HPLC & $(8)$ & 1.4 \\
HPLC & $(9)$ & $1.7 \pm 0.2$ \\
RIA & $(10)$ & $2.0 \pm 1.0$ \\
Pisano technique & $(11)$ & $3.2 \pm 1.6$ \\
Pisano technique & $(12)$ & $4.5 \pm 2.4$ \\
Pisano technique & $(13)$ & $3.3 \pm 1.5$ \\
Pisano technique & $(14)$ & $3.5 \pm 1.5$ \\
Our method & $1.6 \pm 0.8$ \\
\hline * GC $=$ gas chromatography & \\
MS $=$ mass spectrometry & \\
RIA $=$ radioimmunoassay & \\
HPLC $=$ high performance liquid chromatography \\
** values were given as $1.5 \pm 0.6 \mu$ mol/g creatinine which \\
converts to 1.0 \pm 0.4 $\mu$ mol/24 hours, assuming a daily \\
excretion of 1500 mg creatinine.
\end{tabular}

The upper limit for normal metanephrine excretion as determined with the Pisano technique is usually taken as $5 \mu \mathrm{mol}$ per 24 hours $(12,13)$. Three out of 39 samples in our laboratory exhibited values just above this limit when determined from the absorbance at $360 \mathrm{~nm}$; all of them were reduced to values below $3 \mu \mathrm{mol} / 1$ with our method of calculation. The upper limit of normal with our method appears to be considerably lower: no values above $3.2 \mu \mathrm{mol}$ per 24 hours have been observed yet.

In conclusion we believe that our adaptation of the method of calculation of the vanillin concentration will greatly contribute to the reliability and diagnostic accuracy of spectrophotometric assays for total metanephrines. Recoveries for metanephrine were determined by adding $0.5 \mathrm{ml}$ stock solutions to $10 \mathrm{ml}$ pooled urine. The endogenous metanephrine concentration was increased $0-10 \mu \mathrm{mol} / 1$ by the stock additions. These samples were hydrolysed and assayed as described in the materials and methods section. Metanephrine was recovered to the extend of 99.7 $\pm 23.5 \%(n=6)$, in agreement with reports from other authors $(11,14)$. The high value of the standard deviation is the result of the wide range $(0-10$ $\mu \mathrm{mol} / \mathrm{l})$ of metanephrine concentrations, and the low number of determinations.

Because of the simple equipment needed, this modification of the original Pisano technique (11) provides a screening method for phaeochromocytoma that is suitable for even small laboratories. 


\section{References}

1. Remine, W. H., chong, G. C., van Heerden, J. A., Sheps, S. G. \& Harrison, E. G. (1974) Ann. Surg. 179, 740-748.

2. Plouin, P. F., Duclos, J. M., Menard, J., Comoy, E., Bohuon, C. \& Alexandre, J. (1981) Br. Med. J. 282, $853-$ 854.

3. Manu, P. \& Runge, L. A. (1984) Am. J. Epidemiol. 120, $788-790$.

4. Moyer, T. P., Jiang, N. S., Tyce, G. M. \& Sheps, S. G. (1979) Clin. Chem. 25, 256-263.

5. Muskiet, F. A. J. (1979) Ph. D. thesis, State University of Groningen, the Netherlands.

6. Raum, W. J. \& Swerdloff, R. S. (1981) Clin. Chem. 27, 43-47.

7. Canfell, C., Binder, S. R. \& Khayam-Bashi, H. (1982) Clin. Chem. 28, 25-28.

8. Jackman, G. P. (1982) Clin. Chim. Acta 120, 137-142.

9. Buu, N. T., Angers, M., Chevalier, D. \& Kuchel, O. (1984) J. Lab. Clin. Med. 104, 425-432.
10. Iiuma, K., Ikeda, I., Ogihara, T., Hashizume, K., Kurata, K. \& Kumahara, Y. (1986) Clin. Chem. 32, 1879-1883.

11. Pisano, J. J. (1960) Clin. Chim. Acta 5, 406-414.

12. Bravo, E. L., Tarazi, R. C., Gifford, R. W. \& Stewart, B. H. (1979) N. Engl. J. Med. 301, 682-686.

13. Crout, J. R., Pisano, J. J. \& Sjoerdsma, A. (1961) Am. Heart. J. 61, 375-381:

14. Crawford, G. A., Gallery, E. D. M. \& Gyory, A. Z. (1986) Clin. Chim. Acta 157, 121-126.

15. Crowley, J. R., Couch, M. W., Williams, C. M., Threatte, R. M. \& Fregly, M. J. (1981) Clin. Chim. Acta 109, 125= 131.

16. Kobayashi, K., Foti, A., Dequattro, V., Kolloch, R. \& Miano, L. (1980) Clin. Chim. Acta 107, 163-173.

17. Eriksson, B. M. \& Persson, B. A. (1987) J. Chromatogr. $386,1-9$.

Dr. H. J. M. van Rijn

Clinical and Haematological Laboratory

Dr. A. Mathijsen Hospital

P. O. Box 90000

NL-3509 AA Utrecht 